\title{
A pre-post pilot study of peer nutritional counseling and food insecurity and nutritional outcomes among antiretroviral therapy patients in Honduras
}

\author{
Kathryn P. Derose ${ }^{1 *}$, Melissa Felician², Bing Han ${ }^{1}$, Kartika Palar ${ }^{3}$, Blanca Ramírez ${ }^{4}$, Hugo Farías ${ }^{5}$
} and Homero Martínez ${ }^{1,6}$

\begin{abstract}
Background: Food insecurity and poor nutrition are key barriers to anti-retroviral therapy (ART) adherence. Culturally-appropriate and sustainable interventions that provide nutrition counseling for people on ART and of diverse nutritional statuses are needed, particularly given rising rates of overweight and obesity among people living with HIV (PLHIV).

Methods: As part of scale-up of a nutritional counseling intervention, we recruited and trained 17 peer counselors from 14 government-run HIV clinics in Honduras to deliver nutritional counseling to ART patients using a highly interactive curriculum that was developed after extensive formative research on locally available foods and dietary patterns among PLHIV. All participants received the intervention; at baseline and 2 month follow-up, assessments included: 1) interviewer-administered, in-person surveys to collect data on household food insecurity (15-item scale), nutritional knowledge (13-item scale), dietary intake and diversity (number of meals and type and number of food groups consumed in past 24 h); and 2) anthropometric measures (body mass index or BMl, mid-upper arm and waist circumferences). We used multivariable linear regression analysis to examine changes pre-post in food insecurity and the various nutritional outcomes while controlling for baseline characteristics and clinic-level clustering.

Results: Of 482 participants at baseline, we had complete follow-up data on 356 (74\%), of which $62 \%$ were women, median age was $39,34 \%$ reported having paid work, $52 \%$ had completed primary school, and $34 \%$ were overweight or obese. In multivariate analyses adjusting for gender, age, household size, work status, and education, we found that between baseline and follow-up, household food insecurity decreased significantly among all participants $(\beta=-0.47$, $p<.05)$ and among those with children under $18(\beta=-1.16, p<.01)$, while nutritional knowledge and dietary intake and diversity also significantly improved, $(\beta=0.88, p<.001 ; \beta=0.30, p<.001$; and $\beta=0.15, p<.001$, respectively). Nutritional status (BMl, mid-arm and waist circumferences) showed no significant changes, but the brief follow-up period may not have been sufficient to detect changes.
\end{abstract}

Conclusions: A peer-delivered nutritional counseling intervention for PLHIV was associated with improvements in dietary quality and reduced food insecurity among a population of diverse nutritional statuses. Future research should examine if such an intervention can improve adherence among people on ART.

Keywords: HIV, Food insecurity, Nutritional counseling, Lay health workers

\footnotetext{
* Correspondence: derose@rand.org

${ }^{1}$ Health Program, RAND Corporation, Santa Monica, CA, USA

Full list of author information is available at the end of the article
} 


\section{Background}

Food insecurity, defined as "the limited or uncertain availability of nutritionally adequate, safe foods or the inability to acquire personally acceptable foods in socially acceptable ways" [1], and its resultant adverse effects on nutritional status represent important negative influences on HIV outcomes in low-resource settings [2-5]. Studies have found that food insecurity is associated with poor adherence to anti-retroviral therapy (ART) in both resource-poor regions $[4,6-8]$, as well as among vulnerable populations in resource-rich settings [9-12]. Because of the link among food insecurity, poor nutritional status, and adverse HIV outcomes, the World Health Organization (WHO) recommends that interventions to promote initiation of and adherence to ART include attention to a sufficient and balanced diet [13]. Research as to how to provide a healthy diet among PLHIV has identified several approaches: nutrition supplementation (e.g., specialized foods) with or without nutritional education/counseling; safety nets such as food, cash transfer or vouchers; and livelihood interventions such as small scale agriculture, livestock or sewing [14]. These interventions - especially those providing food assistance - have been found to promote positive effects on nutrition status, quality of life, retention in care, adherence to treatment, and household food security among PLHIV $[14,15]$. However, recent research has highlighted that nutrition education and counseling remain weak components of nutritional interventions for PLHIV [14].

Integrating nutrition education and counseling into ART treatment programs is constrained by human capital considerations. Most reported studies of nutritional counseling interventions for PLHIV have relied on professional staff [16-20] and this type of support is limited in low-resource settings. Trained community health workers represent a possible solution. Not only can such an approach contain the cost of delivering nutritional support, but it also offers the linguistic, cultural, and community-building skills to establish rapport with PLHIV. There has been some research into this means of supporting PLHIV: e.g., peer health workers in several countries have been found to be effective in reducing stigma, improving retention in care, and improving quality and outcomes of HIV care [21-26]. However, we are unaware of any reports of the effectiveness of peer nutritional counselors among PLHIV.

Here we examine the feasibility and preliminary effectiveness of a nutritional counseling intervention for PLHIV that was adapted for and delivered by peer counselors in Honduras. Specifically, we examined changes between pre- and post-intervention measures of nutritional knowledge, food insecurity, and dietary quality among people receiving ART. Anthropometric measures were also taken to examine any changes pre- and post-intervention to nutritional status, although funding limitations necessitated a short follow-up period, and thus made these secondary outcomes.

\section{Methods \\ Contextual background}

The study took place within an on-going collaboration between RAND (a non-profit research organization), the United Nations World Food Program (WFP) in Latin America, the Honduran Ministry of Health, and the Honduran National Association of People Living with HIV/AIDS [or Asociación Nacional de Personas Viviendo con VIH/SIDA en Honduras (ASONAPVSIDAH)]. This collaboration was formed to evaluate the role that food aid and nutrition counseling played in supporting HIV care retention, uptake of ART and adherence, and selected clinical outcomes [16]. Specifically, an NIMHfunded parent study used a cluster randomized controlled trial design to compare the effects of a monthly household food basket plus nutrition education versus nutrition education alone on ART adherence of HIV patients at four Comprehensive Treatment Centers in Honduras (referred to here as "HIV clinics"). Nutrition education in the parent study was provided by professional nutritionists who were trained in HIV-related nutritional issues by the study investigators. Although political will existed to extend nutritional counseling at all 38 of the nation's HIV clinics, limited financial and human capital resources made this goal difficult to attain. For example, there was no nutrition training program in the country when the parent study began. Thus, a supplemental pilot study was designed to train peer counselors to provide the nutritional counseling, enabling the scale up of counseling across a larger number of the country's HIV clinics. Although the pilot study was modest in scope (pre- and post- study design with no control group and no randomization, limited measures collected and brief follow-up period), we believe it can make an important contribution given the lack of such interventions in the literature and the need for scalable solutions.

\section{Ethics statement}

The study was approved by RAND's Human Subjects Protection Committee and the Institutional Review Board at the National Autonomous University of Honduras. Written informed consent was obtained from all participants.

\section{Study design}

Fourteen government-run HIV clinics were chosen for the counseling extension project, as these represented the most HIV-affected areas in the country. The clinics provided care to nearly $80 \%$ of patients receiving ART in Honduras, and were in geographical proximity to the four study clinics in the parent study, which served as 
training centers. One or two peer counselors from each center were trained in how to administer the counseling intervention as well as study assessments (anthropometry, nutritional knowledge, dietary intake, food insecurity). All patients receiving ART at each of the 14 clinics over the course of one month were offered the peer nutrition counseling (i.e., there was no randomization); those who provided informed consent to participate in the study were assessed at baseline and 2 months postbaseline, with counseling offered monthly during the study period. This brief follow-up period was necessitated by funding limitations and the parent grant's timeline, though was also considered to be sufficient time to observe change in the more proximate outcomes (e.g., nutritional knowledge and dietary behaviors, including frequency of meals, and dietary diversity).

\section{Theoretical background}

Our nutritional counseling intervention is based on the information-motivation-behavioral skills model [27, 28]. Specifically, we expected that culturally, locally, and HIV appropriate nutrition education would improve nutritional knowledge and dietary intake, which in turn would support a healthy nutritional status and minimize side effects of HIV and ART, such as nausea, diarrhea, oral ulcers, etc. We also expected that locally tailored nutritional education could reduce household food insecurity through improved diet quality, the ability to make the most of existing food resources, and decreased anxiety about procuring healthy food $[29,30]$. Finally, we expected that the nutritional counseling would be reinforced and made even more salient when delivered by peer counselors, who are in similar circumstances (i.e., living with HIV and on ART) and can relate to participants' experiences.

\section{Nutritional counseling intervention}

A nutrition education curriculum with supportive visual aids and a reference technical manual were developed for use by professional nutritionists in the parent study after extensive formative research on locally available foods and dietary patterns among people living with HIV [16]. For the peer counselors, a simplified version of the training manual was developed and supported by educational materials such as flip charts, brochures, and pocket-sized cards meant to reinforce session content. The nutrition education curriculum was based on the WHO/FAO Manual on Nutritional Care and Support for People Living with HIV/AIDS [13, 31] and our formative research, and covered 5 basic topics using concepts and language familiar to this population: 1) consuming a balanced diet; 2) food groups; 3) increasing vitamin and mineral intake through a varied diet; 4) food safety; and 5) how to deal with co-morbidities (diarrhea, acute respiratory infection, nausea, mouth sores, loss of appetite). For example, one way that the curriculum translated complex nutritional information into more understandable constructs is reflected in the conceptualization of different "food groups": 1) alimentos constructores (building foods, or protein); 2) alimentos energéticos (energy foods or carbohydrates and fat); and 3) alimentos reguladores (regulating foods or vitamins and minerals) Further, given the setting and the generally low-income population, the curriculum promoted the most affordable, locally available food and culturally appealing ways to prepare them.

Peer counselors were selected from each of the communities where the HIV clinics were located in collaboration with the Ministry of Health and ASONAPVSIDAH, using the following criteria: HIV status (all peer counselors were HIV positive, ART patients); age 18+ years; completion of middle-school; full time availability for the training and project activities, and demonstrated leadership capability. Over a two-month period, peer counselors received $290 \mathrm{~h}$ of training (intensive workshop and practical training in one of the parent grant's 4 study clinics-see Table 1 for training topics). Thirty-seven lay workers participated in the workshop training; 20 scored at least $75 \%$ correct during the post-workshop assessments and were invited to participate in the practical training under supervision of the parent grant nutritionists; of these 17 were approved as certified Peer Nutritional Counselors, based on their performance during training. Certification was issued by the Honduran Ministry of Health, WFP and RAND, and was

Table 1 Overview of training provided to peer nutrition counselors

\begin{tabular}{lll}
\hline Training settings & Total hours & Topics covered \\
\hline 5 day intensive workshop & 50 & 1. Nutrition and healthy eating \\
& 2. HIV, nutrition and food security \\
& 3. ART and adherence \\
& 4. How to manage secondary effects of ART through diet \\
& 5. Anthropometry and dietary assessment \\
& 1. How to deliver nutritional counseling \\
"Centro de Atención Integral" & 2. How to use supportive educational materials \\
& 3. How to administer evaluation questionnaires (food frequency recall, anthropometry)
\end{tabular}


meant to help these workers be considered for future jobs once the project was completed. The peer nutritional counselors were paid for all their time on this project, including training, practicum, and implementation of the pilot.

Each peer nutritional counselor worked out of their local HIV clinic, in a private working space. Participants were recruited through referrals from medical and nursing staff and from the clinic waiting room. Once informed consent was granted, the counselor collected baseline information (survey and anthropometric measurements), delivered the nutritional counseling, and scheduled a date for a followup visit in one month, coinciding with the regular monthly visit to the clinic required to retrieve HIV medications. The nutritional counseling, which usually lasted an hour, was tailored to each individual, was highly participatory, and encouraged participants to share concerns about eating and learn about where to obtain certain foods and how to prepare them. The peer counselor shared his/her own experience about how eating a better diet had helped him/ her have a better quality of life.

\section{Outcomes}

Food insecurity was assessed using the validated Latin American and Caribbean Food Security Scale (ELCSA), which captures experiences of household food security over a specified time period (we used previous month for this pilot study), including food quantity and sufficiency, food quality and safety, and anxiety about food supplies [32]. Respondents with children $<18$ in the household are asked the full 15-item scale; respondents without children are asked the 8-item version of the scale. All questions received "yes" or "no" answers; raw scores were then tabulated as the sum of affirmative answers, with higher scores indicating higher levels of food insecurity. To maximize data in this intervention pilot, we calculated one food insecurity score (on a scale of $0-8$ ) for all respondents and a separate food insecurity score (on a scale of 0-15) for those with children.

Nutritional knowledge was assessed through 13 "true/ false" statements that were based on key concepts from the nutrition education curriculum such as the importance of eating a variety of food groups, foods that address anemia, and foods that prevent (and address) constipation and diarrhea. Correctly answered items summed to create a score from 0 (no items answered correctly) to 13 (all items answered correctly).

Dietary intake was assessed using a $24 \mathrm{~h}$ qualitative recall. Given the focus of the nutrition education curriculum on increasing the frequency of meals and diversity of food types consumed, supervising nutritionists coded the dietary data for each participant to indicate: 1 ) the number of times participants reported having eaten in the last $24 \mathrm{~h}$; and 2) the number of different food types consumed at each meal (energéticos or carbohydrates and fat, constructores or protein, and reguladores or vitamins and minerals) to create a measure of dietary diversity.

Nutritional status was assessed using Body Mass Index (BMI) and mid-arm and waist circumference measurements taken by the peer counselors, who were trained by the parent grant nutritionists and standardized according to accepted methods [33]. For descriptive statistics, we use World Health Organization classifications of underweight $(<18.5)$, normal (18.5 to 24.9), overweight (25.0 to 29.9), and obese ( $\geq 30)$ [34].

\section{Covariates}

Socio-demographic characteristics included gender, age, household size, whether the participant had completed at least primary level education, and whether the participant currently had paid work (yes/no).

\section{Analysis}

We conducted descriptive analyses to characterize the sample and then multivariable linear regression analysis examining pre- and post-intervention changes (comparing baseline and 2 month follow-up) in food insecurity, nutritional knowledge, dietary intake (number of times eaten and diversity of diet), and nutritional status (BMI and midarm and waist circumference), while controlling for baseline characteristics that could potentially confound the outcomes, including gender, age, education, and work status. Random effects were used to control for the correlations between repeated measures for each participant and the clustering of participants within each clinic. Among 482 participants at baseline, we had follow-up data for 364 (76\%). Of these, 8 were missing data on covariates used in the analyses, thus the final analytic sample was 356 adults. We did not have data on adherence to the nutritional counseling, thus the results represent an intention to treat analysis. We fitted the proposed model using the restricted maximum likelihood, which is a consistent estimator under the missing at random assumption. This approach is particular suitable when most missing data cases are in the outcome variables.

\section{Results}

\section{Baseline characteristics}

Table 2 summarizes the socio-demographic characteristics and primary outcomes for the sample at baseline, first among the final analytic sample $(n=356)$ and then among those who dropped out or were missing data $(n=126)$. Most of those in the analytic sample were women (62\%), Mestizo (85\%), and had at least a primary level education (52\%), a median age of 40 years, and a mean household size of 4 people. Labor force participation was generally low, especially among women (22\% reported currently working compared to $53 \%$ of men). Study dropouts were generally similar to the analytic sample, but had a smaller 
Table 2 Participants' socio-demographic characteristics and baseline measures of study outcomes $(n=356)$

\begin{tabular}{|c|c|c|c|c|}
\hline \multirow{3}{*}{ Characteristics } & \multicolumn{3}{|c|}{ Study completers } & \multirow{3}{*}{$\begin{array}{l}\text { Study dropouts } \\
\text { All } \\
(n=126)\end{array}$} \\
\hline & Women & Men & All & \\
\hline & $(n=220)$ & $(n=136)$ & $(n=356)$ & \\
\hline Female, \% & .. & .. & 61.8 & 61.2 \\
\hline \multicolumn{5}{|l|}{ Ethnic group, \% } \\
\hline Indigenous & 2.8 & 0.8 & 2.0 & 1.2 \\
\hline Mestizo & 81.6 & 90.2 & 84.9 & 90.5 \\
\hline Afro descendants & 14.8 & 9.0 & 12.6 & 8.3 \\
\hline Other/Don't know/Not stated & 0.8 & 0.0 & 0.5 & 0.0 \\
\hline Median age [IQR] & $39.0[16.0]$ & $38.0[15.0]$ & $40.0[15.0]$ & $39.0[15.0]$ \\
\hline Median household size, $\mathrm{n}$ [IQR] & $4.0[2.5]$ & $4.0[3.0]$ & $4.0[2.5]$ & $4.0[2.7]$ \\
\hline Actually has work, $\%$ & 22.3 & 52.9 & 34.0 & 35.7 \\
\hline Completed primary level education, $\%$ & 46.8 & 61.0 & 52.2 & 44.6 \\
\hline \multicolumn{5}{|l|}{ Baseline measures of study outcomes } \\
\hline Median 8-item food insecurity score ${ }^{a}[\mathrm{QQR}]$ & $6.0[5.0]$ & $6.0[5.0]$ & $6.0[5.0]$ & $6.0[5.0]$ \\
\hline Median 15 -item food insecurity score ${ }^{a}[\mathrm{IQR}]$ & $11.0[9.0]$ & $8.0[10.0]$ & $9.5[8.0]$ & $10.0[8.0]$ \\
\hline Median nutritional knowledge score [IQR] & $11.0[2.0]$ & $11.0[2.0]$ & $11.0[2.0]$ & $11.0[4.0]$ \\
\hline Median \# times ate in past 24 hours [IQR] & $3.0[1.0]$ & $4.0[1.0]$ & $4.0[1.0]$ & $3.5[1.0]$ \\
\hline Median \# food types at meals (past 24 hrs) [IQR] & $2.0[2.0]$ & $2.0[1.0]$ & $2.0[2.0]$ & $2.0[2.0]$ \\
\hline Median Body Mass Index [IQR] & $23.4[7.1]$ & $21.6[5.4]$ & $22.5[6.6]$ & $21.3[6.1]$ \\
\hline Underweight $(<18.5), \%$ & 7.3 & 10.3 & 8.4 & 21.4 \\
\hline Normal (18.5-24.9), \% & 49.1 & 61.8 & 54.0 & 51.8 \\
\hline Overweight (25.0-29.9), \% & 26.4 & 19.9 & 23.9 & 17.0 \\
\hline Obese $(30.0+), \%$ & 17.3 & 8.1 & 13.8 & 9.8 \\
\hline Median mid-arm [IQR] & $27.0[6.1]$ & $27.0[4.0]$ & $27.0[5.6]$ & $26.0[4.1]$ \\
\hline Median Waist circumference [IQR] & $85.0[17.0]$ & $80.2[14.0]$ & $83.0[16.0]$ & $83.0[16.0]$ \\
\hline
\end{tabular}

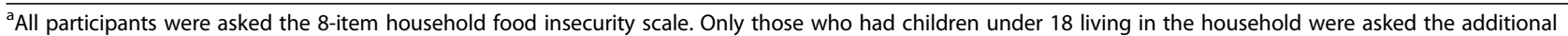
7 items on children and thus are included under the 15-item food insecurity measure

percentage of completely primary level education (45\%), and a BMI distribution more skewed to the left (i.e. towards lower BMI).

In terms of outcomes, levels of food insecurity were generally high, with a median of 6 on the 8 -item scale and 9 on the 15-item scale, both indicating "moderate" food insecurity. Nutritional knowledge was also generally high, with a median of 11 correctly answered items out of 13 . Median number of times eaten in past $24 \mathrm{~h}$ was 4 and median number of food types eaten per meal in past $24 \mathrm{~h}$ was 2 . Median BMI was $23 \mathrm{~kg} / \mathrm{m}^{2}$, while median arm and waist circumferences were $27.4 \mathrm{~cm}$ and $83.5 \mathrm{~cm}$, respectively.

\section{Multivariable regression analyses (Table 3 )}

Household food insecurity decreased on average between baseline and follow-up among all participants $(n=356,8$ item scale, $\beta=-0.47, p<.05)$ and among those with children under $18(n=303,15$-item scale, $\beta=-1.16, p<.01)$. Not working currently was associated with greater food insecurity on both scales $(\beta=0.48, p<.05$ and $\beta=1.26$, $p<.01$, respectively), as was not having completed a primary school education $(\beta=0.95, p<.001$ and $\beta=$ $2.14, p<.001$, respectively).

Nutritional knowledge also improved between baseline and follow-up $(\beta=0.88, p<.001)$. Not having completed a primary school education was associated with lower nutritional knowledge $(\beta=-0.25, p<.05)$.

Dietary intake improved in terms of the number of times participants ate in the past $24 \mathrm{~h}(\beta=0.30, p<.001)$ and the average number of different types of foods consumed at each meal $(\beta=0.15, p<.001)$. Less than complete primary education was associated with worse dietary intake on these two measures $(\beta=-0.18, p<.05$ and $\beta=-0.12, p<.01$, respectively).

Nutritional status as measured by BMI and mid-arm and waist circumferences showed no significant changes between baseline and 2 month follow-up. Female gender was associated with higher BMI $(\beta=1.42, p<.001)$ and age was associated with higher mid-arm and waist circumferences $(\beta=0.04, p<.05$ and $\beta=0.12, p<.01$, 
Table 3 Pre- and post-intervention changes in food insecurity and nutritional outcomes ${ }^{ \pm}$

\begin{tabular}{|c|c|c|c|c|c|c|c|c|}
\hline \multirow[t]{2}{*}{ Variable } & $\begin{array}{l}\text { Food insecurity } \\
\text { (8 items) }\end{array}$ & $\begin{array}{l}\text { Food insecurity } \\
\text { (15 items) }\end{array}$ & $\begin{array}{l}\text { Nutritional } \\
\text { knowledge } \\
\text { (13 items) }\end{array}$ & $\begin{array}{l}\text { \# eating } \\
\text { occasions } \\
\text { in past } 24 \mathrm{~h}\end{array}$ & $\begin{array}{l}\text { \# food types } \\
\text { at each meal } \\
(24 \mathrm{~h})\end{array}$ & BMl & Mid arm circum. & Waist circum. \\
\hline & $N=356$ & $N=303$ & $N=356$ & $N=364$ & $N=364$ & $N=356$ & $N=356$ & $N=356$ \\
\hline $\begin{array}{l}\text { Nutritional counseling } \\
\text { treatment }\end{array}$ & $-0.47(0.19)^{*}$ & $-1.16(0.40)^{* *}$ & $0.88(0.11)^{* * *}$ & $0.30(0.07)^{* * *}$ & $0.15(0.04)^{* * *}$ & $-0.30(0.38)$ & $-0.10(0.40)$ & $-1.46(0.84)$ \\
\hline Female gender & $0.20(0.32)$ & $0.49(0.71)$ & $0.25(0.17)$ & $0.03(0.08)$ & $-0.16(0.06)^{*}$ & $1.42(0.42)^{* * *}$ & $-0.69(0.63)$ & $1.60(0.94)$ \\
\hline Age & $-0.01(0.01)$ & $0.00(0.02)$ & $0.00(0.00)$ & $0.00(0.00)$ & $0.00(0.00)$ & $0.03(0.02)$ & $0.04(0.02)^{*}$ & $0.12(0.04)^{* *}$ \\
\hline Household size & $-0.03(0.04)$ & $0.04(0.08)$ & $0.00(0.02)$ & $0.01(0.01)$ & $0.01(0.01)$ & $0.14(0.08)$ & $0.13(0.08)$ & $0.48(0.17)^{* *}$ \\
\hline Not working & $0.48(0.23)^{*}$ & $1.26(0.47)^{* *}$ & $-0.22(0.13)$ & $-0.16(0.08)$ & $-0.04(0.05)$ & $0.42(0.45)$ & $0.56(0.47)$ & $0.84(0.99)$ \\
\hline $\begin{array}{l}\text { Less than completed } \\
\text { primary ed. }\end{array}$ & $0.95(0.20)^{* * *}$ & $2.14(0.41)^{* * *}$ & $-0.25(0.11)^{*}$ & $-0.18(0.07)^{*}$ & $-0.12(0.04)^{* *}$ & $-0.590 .40)$ & $-0.26(0.42)$ & $-1.15(0.88)$ \\
\hline
\end{tabular}

respectively). Larger household size was also associated with higher waist circumference $(\beta=0.48, p<.01)$.

\section{Discussion}

A culturally and locally appropriate nutritional counseling intervention delivered by peer counselors was significantly associated with improved nutritional knowledge and dietary intake (diversity and frequency) among PLHIV in Honduras. Furthermore, even after controlling for other indicators of socioeconomic status, the intervention was significantly associated with improved food security. The results fill an important gap in evidence addressing the need for effective, sustainable nutrition education and counseling interventions for PLHIV in resource-limited settings [30]. To our knowledge, ours is the first study to demonstrate that a peer-delivered nutritional counseling intervention for PLHIV in resourcelimited settings may improve dietary quality and reduce food insecurity among a population of diverse nutritional statuses (underweight, normal weight, and overweight and obese individuals).

The finding that peer nutrition education was associated with improved food insecurity is especially notable given the persistent negative effects of food insecurity on ART adherence [35] and subsequent immunologic and virologic outcomes [36, 37], as well as its association with higher morbidity [3] and mortality among PLHIV $[38,39]$. Our counseling intervention focused not only on how to obtain good nutrition using locally available foods but also how to make the most of existing resources for food, which may have decreased food insecurity. The fact that peers delivered the counseling, sharing from their own experiences, likely made the strategies even more salient. The parent grant, which used randomization to assign individuals to study groups, found that nutritional education (both alone and in concert with a monthly household food basket), when delivered by trained nutritionists, significantly improved food security [40] and adherence across three adherence outcomes (missed clinic appointments, delayed prescription refills, and self-reported missed doses of ART) [16]. Additional research is needed to determine if peerdelivered nutritional counseling can improve adherence among people on ART.

Peer nutritional education may be especially important in low-resource settings with high prevalence of overweight and obesity among food insecure PLHIV. The parent study found that nutrition education delivered by trained nutritionists significantly improved weight, with overweight and obese patients at baseline losing weight and underweight and normal weight patients gaining weight over the 12 month follow-up [40]. However, when evaluating the addition of food support to nutritional education, food support had the undesired effect of increasing weight significantly among already overweight and obese patients [40]. Further, food supplementation or aid is usually not sustainable in the long-term and thus may fail to address upstream and downstream health consequences [41]. Thus, a nutritional counseling intervention, in addition to being more scalable and sustainable than food support (particularly when delivered by peer counselors), might be more universally appropriate across settings where wasting or underweight is not the primary concern. Indeed, overweight and obesity among PLHIV is of increasing concern across multiple settings and in particular among those on ART, which can lead to increased risk of other chronic conditions including diabetes and cardiovascular disease [42, 43].

Our study had several limitations. The short follow-up period limited our ability to assess effects of the peer nutritional counseling on nutritional status (BMI, body circumferences) and ART adherence. Further, although dropouts 
and the analytic sample were similar in observed characteristics, we do not know whether the dropouts were systematically different from study completers in unobserved characteristics (such as morbidity or mortality); if so, this could result in selection bias and affect the estimated effects. Finally, our study is based on a pre-post comparison with only one study arm, thus we are unable to control for any secular trend in outcomes unrelated to the peer nutritional counseling. However, given the relatively short study period, it is unlikely that any such secular trend occurred.

\section{Conclusions}

Addressing the nutritional needs and food security of PLHIV with feasible, evidence-based, locally-tailored approaches is essential to sustainably improve HIV outcomes. The nutritional education model presented in this paper provides an example of how training peer leaders to deliver HIV-specific nutritional counseling may improve key nutritional outcomes using readily available human capital. This approach has the potential to increase scalability and cultural relevance compared to approaches that rely on professional nutritionists. Our study fills a key gap in the literature on nutrition education and counseling interventions for PLHIV in resource-limited settings and future studies should rigorously test the effectiveness of peer-led nutritional education models on ART adherence and HIV outcomes.

\section{Abbreviations}

ART: Antiretroviral Therapy; PLHIV: People living with HIV; HIV: Human immunodeficiency virus; BMI: Body Mass Index; WHO: World Health Organization; AIDS: Acquired immune deficiency syndrome;

ASONAPVSIDAH: Asociación Nacional de Personas Viviendo con VIH/SIDA en Honduras (in English: National Association of People living with HIV/AIDS in Honduras); FAO: Food and Agriculture Organization; WFP: World Food Program; ELCSA: Escala Latinoamericana y Caribeña de Seguridad Alimentaria (Latin American and Caribbean Scale of Food Security); NIMH: National Institute of Mental Health.

\section{Competing interests}

The authors have no competing interests to declare.

\section{Authors' contributions \\ HM developed the peer nutritional counseling intervention and trained the peer counselors. KPD, HM, and KP conceptualized and designed the present study to assess impacts of the intervention. HM, HF, and BR led field implementation. $\mathrm{KPD}, \mathrm{BH}$, and MF analyzed the data. $\mathrm{KPD}, \mathrm{BH}, \mathrm{MF}$, and $\mathrm{HM}$ drafted the paper; KP and HF reviewed the paper and provided critical comment. All authors read and approved the final manuscript.}

\section{Authors' information}

KPD is Senior Policy Researcher at the RAND Corporation with extensive experience on community-based health interventions and Latin America. MF is Doctoral Fellow at Pardee RAND Graduate School and has experience with international development programming.

$\mathrm{BH}$ is Statistician at the RAND Corporation with experience applying biostatistics to public health and other public policy areas.

KP is Assistant Professor at the University of California, San Francisco and has expertise assessing food insecurity and its effects on HIV care in Latin America, Africa, and the US.

BR was the WFP Project Manager for field implementation of the peer nutrition counseling intervention.
HF is Regional Capacity Development Advisor for the World Food Program Regional Office for Latin America and the Caribbean and has extensive experience with health-related programming for people with HIV. HM is Senior Natural Scientist (MD) at RAND and has nutrition expertise and extensive experience with community health worker interventions and chronic disease prevention in Latin America.

\section{Acknowledgements}

The peer counseling intervention pilot study was funded by the National Institute of Mental Health (NIMH) (R34MH084675, PI: Martínez). Preparation of this manuscript was supported in part by RAND Health. Its contents are solely the responsibility of the authors and do not represent the official views of NIMH or RAND. The authors thank Alexandria Smith, formerly of RAND, who merged the datafiles from the field and created the dataset that was used in these analyses. They are also grateful to their close collaborators in Honduras who made the study possible: the 17 peer nutrition counselors, clinic staff at the 14 pilot sites, ASONAPVSIDAH and the Ministry of Health.

\section{Author details}

${ }^{1}$ Health Program, RAND Corporation, Santa Monica, CA, USA. ${ }^{2}$ Pardee RAND Graduate School, Santa Monica, CA, USA. ${ }^{3}$ Division of HIV, ID and Global Medicine, Department of Medicine, University of California San Francisco, San Francisco, CA, USA. ${ }^{4}$ Honduran Country Office, United Nations World Food Program, Tegucigalpa, Honduras. ${ }^{5}$ Regional Office for Latin America and the Caribbean, United Nations World Food Program, Panama City, Panama.

${ }^{6}$ Hospital Infantil de México Federico Gómez, Mexico City, Mexico.

Received: 22 May 2015 Accepted: 29 September 2015

Published online: 15 October 2015

\section{References}

1. Anderson SA. Core indicators of nutritional state for difficult-to-sample populations. J Nutr. 1990;120(11 Suppl):1555-600.

2. Marcellin F, Boyer S, Protopopescu C, Dia A, Ongolo-Zogo P, Koulla-Shiro S, et al. Determinants of unplanned antiretroviral treatment interruptions among people living with HIV in Yaounde, Cameroon (EVAL survey, ANRS 12-116). Trop Med Int Health. 2008;13(12):1470-8.

3. Weiser SD, Tsai AC, Gupta R, Frongillo EA, Kawuma A, Senkungu J, et al. Food insecurity is associated with morbidity and patterns of healthcare utilization among HIV-infected individuals in a resource-poor setting. AIDS. 2012;26(1):67-75.

4. Franke MF, Murray MB, Munoz M, Hernandez-Diaz S, Sebastian JL, Atwood S, et al. Food insufficiency is a risk factor for suboptimal antiretroviral therapy adherence among HIV-infected adults in urban Peru. AIDS Behav. 2011;15(7):1483-9.

5. Weiser SD, Tuller DM, Frongillo EA, Senkungu J, Mukiibi N, Bangsberg DR. Food insecurity as a barrier to sustained antiretroviral therapy adherence in Uganda. PLoS One. 2010;5(4):e10340.

6. Boyer $\mathrm{S}$, Clerc I, Bonono CR, Marcellin F, Bile PC, Ventelou B. Non-adherence to antiretroviral treatment and unplanned treatment interruption among people living with HIV/AIDS in Cameroon: Individual and healthcare supply-related factors. Soc Sci Med. 2011;72(8):1383-92.

7. Sasaki Y, Kakimoto K, Dube C, Sikazwe I, Moyo C, Syakantu G, et al. Adherence to antiretroviral therapy (ART) during the early months of treatment in rural Zambia: influence of demographic characteristics and social surroundings of patients. Ann Clin Microbiol Antimicrob. 2012;11:34.

8. Weiser SD, Palar K, Frongillo EA, Tsai AC, Kumbakumba E, Depee S, et al. Longitudinal assessment of associations between food insecurity, antiretroviral adherence and HIV treatment outcomes in rural Uganda. AIDS. 2014:28(1):115-20.

9. Gebo KA, Keruly J, Moore RD. Association of social stress, illicit drug use, and health beliefs with nonadherence to antiretroviral therapy. J Gen Intern Med. 2003;18(2):104-11.

10. Kalichman SC, Cherry C, Amaral C, White D, Kalichman MO, Pope H, et al. Health and treatment implications of food insufficiency among people living with HIV/AIDS, Atlanta, Georgia. J Urban Health. 2010;87(4):631-41.

11. Weiser SD, Yuan C, Guzman D, Frongillo EA, Riley ED, Bangsberg DR, et al. Food insecurity and HIV clinical outcomes in a longitudinal study of homeless and marginally housed HIV-infected individuals in San Francisco. AIDS. 2013;27(18):2953-8. 
12. Peretti-Watel $P$, Spire $B$, Schiltz MA, Bouhnik AD, Heard I, Lert F, et al. Vulnerability, unsafe sex and non-adherence to HAART: evidence from a large sample of French HIV/AIDS outpatients. Soc Sci Med. 2006;62(10):2420-33.

13. WHO. Nutrition Counseling, Care and Support for HIV-Infected Women. Guidelines on HIV-related care, treatment and support for HIV-infected women and their children in resource-constrained settings. Geneva: WHO; 2004.

14. Aberman NL, Rawat R, Drimie S, Claros JM, Kadiyala S. Food security and nutrition interventions in response to the AIDS epidemic: assessing global action and evidence. AIDS Behav. 2014;18:S554-S65.

15. de Pee S, Grede N, Mehra D, Bloem MW. The enabling effect of food assistance in improving adherence and/or treatment completion for antiretroviral therapy and tuberculosis treatment: a literature review. AIDS Behav. 2014;18 Suppl 5:S531-41.

16. Martinez H, Palar K, Linnemayr S, Smith A, Derose KP, Ramirez B, et al. Tailored nutrition education and food assistance improve adherence to HIV antiretroviral therapy: evidence from Honduras. AIDS Behav. 2014;18 Suppl 5:S566-77.

17. Almeida LB, Segurado AC, Duran AC, Jaime PC. Impact of a nutritional counseling program on prevention of HAART-related metabolic and morphologic abnormalities. AIDS Care. 2011;23(6):755-63.

18. Serrano C, Laporte R, Ide M, Nouhou Y, de Truchis P, Rouveix E, et al. Family nutritional support improves survival, immune restoration and adherence in HIV patients receiving ART in developing country. Asia Pac J Clin Nutr. 2010;19(1):68-75.

19. Byron E, Gillespie S, Nangami M. Integrating nutrition security with treatment of people living with HIV: lessons from Kenya. Food Nutr Bull. 2008;29(2):87-97.

20. Ivers L, Chang Y, Jerome J, Freedberg K. Food assistance is associated with improved body mass index, food security and attendance at clinic in an HIV program in central Haiti: a prospective observational cohort study. AIDS Res Ther. 2010;7(33):1-8.

21. Arem H, Nakyanjo N, Kagaayi J, Mulamba J, Nakigozi G, Serwadda D, et al. Peer health workers and AIDS care in Rakai, Uganda: a mixed methods operations research evaluation of a cluster-randomized trial. AIDS Patient Care STDS. 2011;25(12):719-24.

22. Chang LW, Kagaayi J, Nakigozi G, Ssempijja V, Packer AH, Serwadda D, et al. Effect of peer health workers on AIDS care in Rakai, Uganda: a clusterrandomized trial. PLoS One. 2010;5(6):e10923.

23. Gusdal AK, Obua C, Andualem T, Wahlstrom R, Chalker J, Fochsen G, et al. Peer counselors' role in supporting patients' adherence to ART in Ethiopia and Uganda. AIDS Care. 2011;23(6):657-62.

24. Jerome $\mathrm{G}$, Ivers $\mathrm{L}$. Community health workers in health systems strengthening: a qualitative evaluation from rural Haiti. AIDS. 2010;24 Suppl 1:S67-72.

25. Louis C, Ivers LC, Fawzi MCS, Freedberg KA, Castro A. Late presentation for HIV care in central Haiti: factors limiting access to care. AIDS Care. 2007;19(4):487-91.

26. Mukherjee JS, Eustache FE. Community health workers as a cornerstone for integrating HIV and primary healthcare. AIDS Care. 2007;19:S73-82.

27. Fisher JD, Fisher WA. Changing AIDS-risk behavior. Psychol Bull. 1992;111(3):455-74.

28. Fisher JD, Fisher WA, Shupper PA. The information motivation behavioral skills model of HIV preventive behavior. 2nd ed. San Francisco: Jossey Bass; 2009.

29. Eicher-Miller HA, Mason AC, Abbott AR, McCabe GP, Boushey CJ. The effect of food stamp nutrition education on the food insecurity of low-income women participants. J Nutr Educ Behav. 2009;41(3):161-8.

30. Kaye HL, Moreno-Leguizamon CJ. Nutrition education and counselling as strategic interventions to improvehealth outcomes in adult outpatients with HIV: a literature review. Afr J AIDS Res. 2010;9(3):271-83.

31. WHO, UNAIDS, UNICEF. HIV and Infant Feeding Counseling: A Training Course. Director's Guide. Geneva, Switzerland: WHO; 2000.

32. Melgar-Quiñonez H, Cecilia Alvarez Uribe M, Yanira Fonseca Centeno Z, Bermúdez O, Palma de Fulladolsa P, Fulladolsa A, et al. Psychometric characteristics of the food security scale (ELCSA) applied in Colombia, Guatemala y México. Segurança Alimentar e Nutricional, Campinas. 2010;17(1):48-60.

33. Habicht JP. Standardization of quantitative epidemiological methods in the field. Bol Oficina Sanit Panam. 1974;76(5):375-84. Estandarizacion de metodos epidemiologicos cuantitativos sobre el terreno. spa.

34. BMI Classification. Available from: http://apps.who.int/bmi/index.jsp? introPage=intro_3.html. Accessed Jan. 15, 2015.
35. Singer AW, Weiser SD, McCoy SI. Does food insecurity undermine adherence to antiretroviral therapy? A systematic review. AIDS Behav. 2015;19(8):1510-26.

36. McMahon JH, Wanke CA, Elliott JH, Skinner S, Tang AM. Repeated assessments of food security predict CD4 change in the setting of antiretroviral therapy. J Acquir Immune Defic Syndr. 2011;58(1):60-3.

37. Alexy E, Feldman M, Thomas J, Irvine M. Food insecurity and viral suppression in a cross-sectional study of people living with HIV accessing Ryan White food and nutrition services in New York City. Lancet. 2013;382 Suppl 2:S15.

38. Weiser SD, Fernandes KA, Brandson EK, Lima VD, Anema A, Bangsberg DR, et al. The association between food insecurity and mortality among HIV-infected individuals on HAART. J Acquir Immune Defic Syndr. 2009;52(3):342-9.

39. Anema A, Chan K, Chen Y, Weiser S, Montaner JS, Hogg RS. Relationship between food insecurity and mortality among HIV-positive injection drug users receiving antiretroviral therapy in British Columbia, Canada. PLoS One. 2013;8(5):e61277.

40. Palar K, Kushel M, Frongillo EA, Riley ED, Grede N, Bangsberg D, et al. Food insecurity is longitudinally associated with depressive symptoms among homeless and marginally-housed individuals living with HIV. AIDS Behav. 2015;19(8):1527-34.

41. Yager JE, Kadiyala S, Weiser SD. HIV/AIDS, Food Supplementation and livelihood programs in Uganda: a way forward? PloS One. 2011;6(10):e26117.

42. Keithley JK, Duloy AM, Swanson B, Zeller JM. HIV infection and obesity: a review of the evidence. J Assoc Nurses AIDS Care. 2009;20(4):260-74.

43. Finkelstein JL, Gala P, Rochford R, Glesby MJ, Mehta S. HIV/AIDS and lipodystrophy: implications for clinical management in resource-limited settings. J Int AIDS Soc. 2015;18(1):19033.

\section{Submit your next manuscript to BioMed Central and take full advantage of:}

- Convenient online submission

- Thorough peer review

- No space constraints or color figure charges

- Immediate publication on acceptance

- Inclusion in PubMed, CAS, Scopus and Google Scholar

- Research which is freely available for redistribution 